\title{
Role of Hyperglycemia in Isogeneic Islet Transplantation: An Experimental Animal Study
}

Authors

Affiliations

\author{
I. Nomikos ${ }^{1}$, K. Kalogerakos ${ }^{1}$, E. Athanasiou², E. Plakokefales ${ }^{3}$, D. Sioutopoulou², M. Satra², \\ N. C. Vamvakopoulos ${ }^{2}$ \\ 'Department of Surgery (B' Unit), “METAXA” Cancer Memorial Hospital, Piraeus, Greece \\ ${ }^{2}$ Department of Surgery, Medical School, University of Thessaly, Larissa, Greece \\ ${ }^{3}$ Department of Biology and Genetics, Medical School, University of Thessaly, Larissa, Greece
}

\begin{abstract}
$\nabla$

Objective: Study the role of hyperglycemiainduced $\beta$ cell loss on grafted islet destruction.

Design: Male inbred rats were made diabetic by streptozotocin administration and used as islet donors and/or isograft recipients to probe directly the role of hyperglycemia as an important determinant of transplanted islet fate, following exclusion of immune-related causes of islet graft destruction like allograft immunity and disease recurrence.
\end{abstract}

\section{Introduction}

The ultimate objective of pancreatic islet transplantation in the treatment of Type I diabetes is the restoration of normoglycemia in order to prevent or stabilize long-term complications of the disease (Meyer et al., 2007; Ryan et al., 2004; O'Connell et al., 2006). There are two important immune-mediated obstacles to islet grafting in spontaneous diabetes: a) Induction of allograft immunity resulting in graft rejection (Lafferty et al., 1986), and b) Recurrence of disease pathogenesis resulting in graft destruction (Prowse et al., 1986; Nomikos et al., 1986). While these immune processes are critical to understand and overcome, a third potential biological barrier to islet transplantation appears to involve hyperglycemia associated with disease (Biarnes et al., 2002; Unger et al., 1985; Gray et al., 1989).

Studies on pancreatic islet transplantation for the treatment of insulin dependent diabetes mellitus (IDDM) suggested that hyperglycemia itself is sufficient to trigger islet graft destruction (Biarnes et al., 2002). Persistent hyperglycemia has long been suspected of having a detrimental effect on pancreatic islet function (Unger et al., 1985) and there is evidence that long term expo-
Results: Our studies showed that: a) Hyperglycemia destroyed islet but not pituitary isografts and b) Tight control of normoglycemia by sufficient islet mass engraftment prevented graft damage.

Conclusion: While sustained hyperglycemia caused destruction of transplanted islet isografts, induction of normoglycemia by transplantation of sufficient islet mass to diabetic recipients had a beneficial long term effect on their functional engraftment.
Correspondence

Department of Biology

University of Thessaly

Papakuriazi -22

41221 Larissa

Greece

Tel.: + 30/56/50 74

msatra@med.uth.gr sure of islets to hyperglycemia results in beta cell loss (Biarnes et al., 2002; Gray et al., 1989).

In this animal study we attempted to reassess the role of hyperglycemic stress in isogeneic pancreatic islet transplantation.

\section{Material and Methods \\ $\nabla$}

Animals

Male inbred DA $\left(\mathrm{RT}^{\mathrm{a}}{ }^{\mathrm{a}}\right)$, PVG $\left(\mathrm{RT}^{\mathrm{c}}\right)$ and Lewis $\left(\mathrm{RT} 1^{\prime}\right)$ rats (approximately 200 grams) were used as islet donors and recipients.

\section{Induction of diabetes}

Experimental animals were rendered diabetic by intravenous administration of a single bolus of streptozotocin $(55-65 \mathrm{mg} / \mathrm{Kg})$. Diabetes was defined by consecutive blood glucose readings equal to or greater than $20 \mathrm{mmol} / \mathrm{l}$.

\section{Islet preparation, culture and} transplantation

Pancreatic islets were prepared by collagenase digestion and hand picking technique as previously described (Rajotte et al., 1984). Varying numbers of islets were transplanted beneath the kidney capsule of the recipients. Fresh islets were 
transplanted within the matrix of a blood clot from the recipient as described (Babcock et al., 1987). Where indicated islet cells were depleted of antigen presenting cells (APC's) following culture in an atmosphere of 95\% oxygen as described (Lafferty et al., 1987). Islet function in streptozotocin-induced diabetic recipients was determined by blood glucose measurements twice weekly. Graft failure was indicated by persistent blood glucose levels above the $95 \%$ confidence interval for normal rats. The integrity of islet grafts in non-diabetic recipients was determined by histologic analysis 30 days post grafting.

\section{Histology}

Removed kidneys were fixed in formol saline. Paraffin sections were stained with hematoxylin-eosin and aldehyde fuchsin (Nomikos et al., 1986; Sioutopoulou et al., 2006). Immunoperoxidase was used for insulin and glycagon staining (Prowse et al., 1986; Vakalis et al., 1999).

\section{Results}

$\checkmark$

Tissue-specific destruction of cultured islet isografts by hyperglycemia

Six hundred cultured isogeneic islets were transplanted in the upper pole of the recipient's kidney in three different strains of either normal or streptozotocin-primed diabetic rats (PVG's, Lewis's and DA's). Potential generation of an allograft response was monitored by placing a pituitary graft from the same donor in the lower pole of the diabetic recipient's kidney, as an endo-
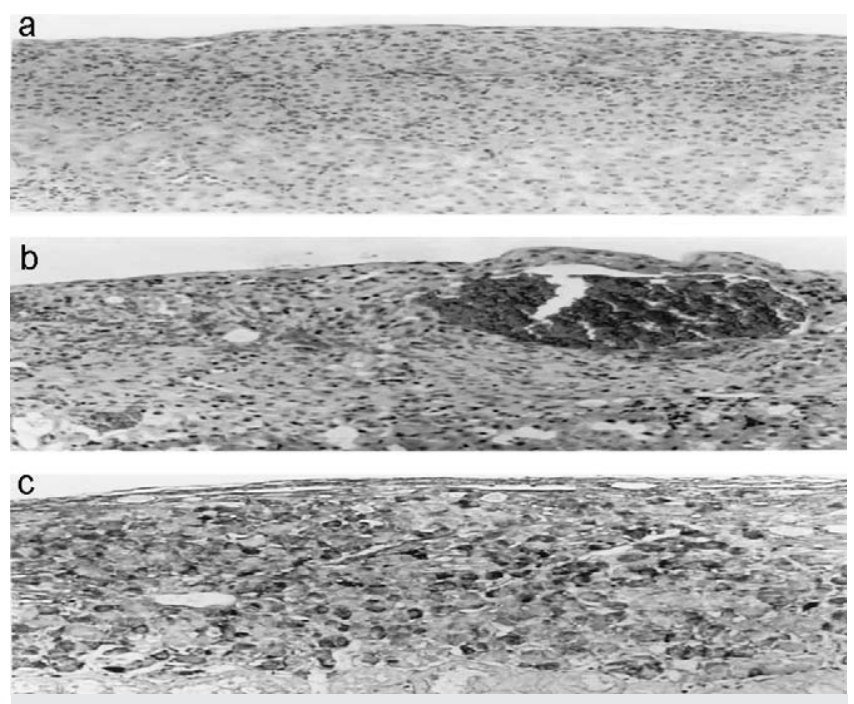

Fig. 1 Histologic documentation of male DA rat isograft fates: a. In the non diabetic recipient, an intact islet isograft underneath the kidney capsule was observed; $\mathbf{b}$. in the diabetic recipient, the islet isograft demonstrated a dramatic degree of tissue disruption characterized by islet vacuolization, hemorrhagic blood lakes, damage of endothelial cells and mononuclear cell accumulation; $\mathbf{c}$. in the diabetic recipient, an intact pituitary graft (endocrine control tissue), with minimal lymphoid infiltration was observed. crine control tissue. Normoglycemia was not attained in any of the diabetic animals. Kidneys carrying the grafts (islets and pituitary) were removed 30 days post grafting and were examined histologically. In the non diabetic recipients the islet grafts remained intact ( $\bullet$ Fig. 1a). However, in the diabetic recipients, the islet grafts demonstrated a dramatic form of tissue disruption characterized by islet vacuolization, hemorrhagic blood lakes, endothelial cell damage, mononuclear cell accumulation, and development of fibrous tissue ( $\bullet$ Fig. 1b). In each case, the pituitary grafts remained intact, with minimal lymphoid infiltration and no other demonstrable damage ( $\bullet$ Fig. 1c). Similar results occurred with each of the three rat strains tested (PVG's, Lewis's and DA's) (Table 1).

\section{Destruction of uncultured islet isografts by hyperglycemia}

In order to exclude a possible culture effect on isografted islets, we tested two groups of 6 animals each grafted with the same preparation of uncultured islets. In the study group, six streptozotocin pretreated DA rats were transplanted by 600 uncultured isogeneic islets via a clot of blood. In the control group, six normal DA rats were transplanted by 600 uncultured isogeneic islets via a clot of blood. Normoglycemia was not attained in any of the diabetic animals tested. Grafts were removed and examined 30 days after transplantation. The results of the histologic examination of the transplants are listed in Table 2.

\section{Protective role of transplanted islet mass in graft damage prevention}

In this set of experiments five diabetic DA's were transplanted by 1000-2000 cultured isogeneic islets. Normoglycemia was attained in all of the diabetic animals in the immediate post transplantation period. The animals remained normoglycemic during the follow up

Table 1 Differential effect of hyperglycemia in islet and pituitary isografts

\begin{tabular}{|c|c|c|}
\hline \multirow[b]{2}{*}{ Strain/\# animals } & \multicolumn{2}{|c|}{ Histology Score ${ }^{1}$} \\
\hline & Islet Graft ${ }^{2}$ & Pituitary ${ }^{2}$ \\
\hline PVG/6 & $1,3,4,4,4$ & $0,0,1,1$ \\
\hline $\mathrm{DA} / 6$ & $2,3,4,4$ & $0,0,0,0$ \\
\hline Lewis/6 & $1,1,4,4,4,4$ & $0,0,0,0,0,0$ \\
\hline \multicolumn{3}{|c|}{$\begin{array}{l}\text { 1Histology Score: } 0 \text {, no damage; } 1 \text {, minor infiltrate; } 2 \text {, moderate inflammatory } \\
\text { infiltrate with islet disruption; } 3 \text {, hemorrhagic lakes in the graft, beta cell vacuoliza- } \\
\text { tion, mononuclear cell accumulation; } 4 \text {, fibrous tissue development and complete } \\
\text { destruction of the graft }\end{array}$} \\
\hline
\end{tabular}

Table 2 Destruction of islet isografts by hyperglycemia

\begin{tabular}{|c|c|c|}
\hline Recipients & Non diabetic & Diabetic \\
\hline Histology Score ${ }^{1}$ & $0,0,1,1,1,2$ & $3,4,4,4,4,4$ \\
\hline \multicolumn{3}{|c|}{$\begin{array}{l}{ }^{1} \text { Histology Score: } 0 \text {, no damage; } 1 \text {, minor infiltrate; } 2 \text {, moderate inflammatory } \\
\text { infiltrate with islet disruption; } 3 \text {, hemorrhagic lakes in the graft, beta cell vacuoliza- } \\
\text { tion, mononuclear cell accumulation; } 4 \text {, fibrous tissue development and complete } \\
\text { destruction of the graft }\end{array}$} \\
\hline
\end{tabular}

Table 3 Function of islet isografts in diabetic recipients

\begin{tabular}{lclllll} 
Number of animals & Number of cultured islets & \multicolumn{5}{c}{ Days of normoglycemia } \\
\hline 6 & 600 &,- &,- &,- &,- &,- \\
6 & 1200 & $>100$, & $>100$, & $>100$, & $>100$, & $>100$,
\end{tabular}


period (more than 100 days) and returned to a hyperglycemic state when the kidney carrying the graft was removed (Table 3 ).

\section{Discussion \\ $\nabla$}

Our present animal study showed that islet tissue isografts either depleted of APC's or not, are destroyed in the hyperglycemic environment. The main histological findings of this type of damage are the complete destruction of endothelium of blood vessels along with the formation of large blood lakes and mononuclear cell accumulation through the grafted tissue ( $\bullet$ Fig. 1b). Islet damage was tissue specific, since pituitary grafts (endocrine tissue control) remained intact in the diabetic rats ( Fig. 1c). To exclude auto- or allo- immune damage and test directly the role of hyperglycemia in islet rejection, we transplanted islet isografts to streptozotocin-primed diabetic animals. The comparable development of hemorrhagic lakes and the associated disruption of vascular endothelium by all three animal strains examined, supported the damaging effect of hyperglycemia in grafted islet destruction. Interestingly, in diabetic animals there was a selective damage of beta cells while the alpha cells remained positive for glycagon (not shown). Further support in favor of the observed impairment of islet graft vascularization by hyperglycemia, was provided by a Swedish study demonstrating the ability of 400 islets to reverse diabetes in streptozotocin-primed diabetic rats treated for a short time during the peritransplantation period with insulin. The same amount of islets did not restore normoglycemia in the non insulin treated animals (Ar' Rajab Ahren et al., 1992). Finally our data indicate that this hyperglycemic damage was not the result of allo immunity from poorly inbred strain, since three different strain combinations showed the same effect (Table 1). In agreement to previous reports our present findings indicated that tight control of blood glucose at the time of transplantation was crucial for long term protection of functional transplanted islets (Merino et al., 2000; Ferrer-Garcia et al., 2003; Morsiani et al., 2002).

The close similarity between the present vascular lesions (hemorrhagic lakes and disruption of vascular endothelium) and those of newly formed small vessels and capillaries at the site of a resent wound (e.g. abdominal wall, intestinal anastomosis), suggested that hyperglycemic vascular damage may also be viewed as an acute perioperative phenomenon (Nomikos et al., 2006). A possible pathophysiologic linkage between high glucose levels and development of vascular endothelial defect was suggested in one study, where hyperglycemia was shown to induce free radical formation and glucose oxidation leading to delay of endothelial cell replication (Inoguchi et al., 1992). Similar findings from another study suggested that high glucose conditions facilitate the susceptibility of serum proteins to sulfhydryl oxidation forming disulfide crosslinks and this oxidative process may contribute to the inhibition of endothelial cell proliferation and early apoptotic death of transplanted islets (Stafani et al., 1992; Emamaullee et al., 2007).

Our findings support the detrimental effect of perioperative hyperglycemic state on new capillary formation at the sites where a healing process is taking place and underscore the protective role of tight normoglycemic control in the prevention of associated surgical complications.

Conflict of interest: None.

\section{References}

1 Ar' Rajab Ahren B. Prevention of hyperglycemia improves the long term results of islet transplantation in streptozotocin - diabetic rats. Pancreas 1992; 7: 435-442

2 Babcock SK, Gill RG, Bellgrau D, Lafferty KJ. Studies on the two signal model for T cell activation in vivo. Transpl Proc 1987; 19 (1): 303-306

3 Biarnes M, Montolio M, Nacher V, Raurell M, Soler J, Montanya E. Betacell death and mass in syngeneically transplanted islets exposed to short- and long-term hyperglycemia. Diabetes 2002; 51: 66-72

4 Emamaullee JA, Stanton L, Schur C, Shapiro AM. Caspase inhibitor therapy enhances marginal mass islet graft survival and preserves long-term function in islet transplantation. Diabetes 2007; 56: 1289-1298

5 Ferrer-Garcia JC, Merino-Torres JF, Perez Bermejo G, Herrera-Vela C, Ponce-Marco JL, Pinon-Selles F. Insulin induced normoglycemia reduces islet number needed to achieve normoglycemia after allogeneic islet transplantation in diabetic mice. Cell Transplant. 2003; 12: 849-857

6 Gray DWR, Cranston D, MacShane P, Sutton R, Morris PJ. Preferential effect of hyperglycemia on pancreatic islets transplanted into rats beneath the kidney capsule. Diabetologia 1989; 32: 663-667

7 Inoguchi T, Battan R, Handler E, Sportsman JR, Heath M, King GL. Preferential elevation of protein kinase $C$ isoform beta II and diacylglycerol levels in the aorta and heart of diabetic rats: differential reversibility to glycemic control by islet transplantation. Proc Natl Acad Sci 1992; 89: 1059-1063

8 Lafferty KJ, Gill RL, Babcock SK, Simeonovic CJ. Activation and expression of allograft immunity. In: Progress in Transplantation 1986; 55-84

9 Lafferty KJ, Prowse SJ, Simeonovic CJ. Immunobiology of tissue transplantation: a return to the passenger leucocyte concept. Annu Rev Immunol 1983; 1: 143-173

10 Merino JF, Nacher V, Raurell M, Biarnes M, Soler J, Montanya E. Optimal insulin treatment in syngeneic islet transplantation. Cell Transplant 2000; 9: 11-18

11 Meyer C. Islet transplantation. N Engl J Med 2007 Mar 1; 356 (9): 963; author reply 964-965

12 Morsiani E, Fogli L, Lanza Jr G, Lebow LT, Demetriou AA, Rozga J. Long-term insulin independence following repeated islet transplantation in totally pancreatectomized diabetic pigs. Cell Transplant 2002; 11: 55-66

13 Nomikos IN, Malizos C, Vamvakopoulos NC. Protective and damaging effects of healing. Wounds 2006; 18: 177-185

14 Nomikos IN, Prowse SJ, Carotenuto P, lafferty KJ. Combined treatment with nicotinamide and desferrioxamine prevents islet allograft destruction. Diabetes 1986; 35: 1302-1304

15 O'Connell PJ, Hawthorne WJ, Holmes-Walker DJ, Nankivell BJ, Gunton JE, Patel AT, Walters SN, Pleass HC, Allen RD, Chapman JR. Clinical islet transplantation in type 1 diabetes mellitus: results of Australia's first trial. Med J Aust 2006; 184 (5): 221-225

16 Prowse SJ, Bellgraau D, Lafferty KJ. Islet allografts are destroyed by disease recurrence in spontaneous diabetic BB rat. Diabetes 1986; 35: 110-114

17 Rajotte RV, Warnock GL, Kneteman NM. Cryopreservation of insulinproducing tissue in rats and dogs. World J Surg 1984; 8: 179-186

18 Ryan EA, Shandro T, Green K, Paty BW, Senior PA, Bigam D, Shapiro AM, Vantyghem MC. Assessment of the severity of hypoglycemia and glycemic lability in type 1 diabetic subjects undergoing islet transplantation. Diabetes 2004; (4): 955-962

19 Sioutopoulou D, Plakokefalos E, Anifandis G, Arvanitis L, Venizelos I, Valery R, Destouni H, Vamvakopoulos NC. Comparing normal primary endocervical adenoepithelial cells to uninfected and influenza B virus infected human cervical adenocarcinoma HeLa cells. Int J Gynecol Cancer 2006; 16: 2032-2038

20 Stafani MR, Dunlap JA, Yorek MA. Effect of L-fucose on proliferation and myo-inositol metabolismin cultured cerebral microvessel and aortic endothelial cells. J Cell Physiol 1992; 153: 321-331

21 Unger RH, Grundy S. Hyperglycemia as an inducer as well as a consequence of impaired islet cell function and insulin resistance: implications for the management of diabetes. Diabetologia 1985; 28: 118-121

22 Vakalis NC, Spanacos G, Patsoula A, Vamvakopoulos NC. Improved detection of Dirofilaria repens DÍÁ by direct polymerase chain reaction. Parasitology International 1999; 48: 145-150

\section{Erratum}

Please note that the correct author's name is E. Plakokefalos. 